\title{
A Controlled Trial of Assisted Ventilation Using an Oro-nasal Mask ${ }^{*}$
}

\author{
M. A. LLEWELLYN, K. S. TILAK, and P. R. SWYER \\ From the Research Institute of The Hospital for Sick Children and the Department of Paediatrics, \\ University of Toronto, Toronto, Ontario
}

\begin{abstract}
Llewellyn, M. A., Tilak, K. S., and Swyer, P. R. (1970). Archives of Disease in Childhood, 45, 453. A controlled trial of assisted ventilation using an oro-nasal mask. A controlled study was performed to assess the effect of early assisted ventilation using a tight fitting face mask. Early mask ventilation reduced the number of infants requiring intubation, but did not significantly alter the survival rate.

Complications were seen in infants during both mask ventilation and ventilation with a naso-tracheal tube. Persistent radiological changes were seen in 5 of 9 infants who survived after ventilation for more than 5 days..
\end{abstract}

Since the introduction of assisted ventilation in the management of the respiratory distress syndrome (RDS), numerous centres have reported their results of this form of therapy using both positive pressure and negative pressure ventilators (Adamson et al., 1968; Benson et al., 1958; Cooke et al., 1967; Delivoria-Papadopoulos, Levison, and Swyer, 1965; Donald and Lord, 1953; Heese, Wittmann, and Malan, 1963; Malan et al., 1967; Murdock et al., 1970; Reid, Tunstall, and Mitchell, 1967; Silverman et al., 1967; Stahlman, Young, and Payne, 1962; Stern et al., 1968; Thomas et al., 1965). Most centres use an oro-tracheal or naso-tracheal tube to apply intermittent positive pressure ventilation (IPPV). It has become evident that the advantages of such a technique must be weighed against its complications. Tube displacement and blockage are a constant hazard. Laryngeal oedema and loss of ciliated tracheal mucosa with ulceration are common necropsy findings after prolonged intubation, and these predispose to permanent laryngeal and tracheal damage. Infection is readily established in these infants, doubtless due in part to the repeated introduction of suction catheters.

Assisted ventilation with a tight fitting face mask would avoid these difficulties and hence could be more readily applied at an earlier stage in the disease. Early, effective IPPV would theoretically prevent progressive atelectasis, with the accompanying fall

\footnotetext{
Received 26 January 1970.

«Supported by Grant No. MT-2497 from the Medical Research Council of Canada.
}

in pulmonary compliance and increasing work load (Cooke et al., 1957; Nelson et al., 1963).

In view of the variation in the course of RDS, it is essential to evaluate any new approach to therapy as a controlled study. This study was designed to assess the effect of early mask ventilation on the course of the disease and on survival.

\section{Subjects and Methods}

During the nine-month period May 1968 to March 1969,127 infants were admitted to the unit with a clinical and radiological diagnosis of RDS, all being referred from obstetric units outside the hospital. On admission, umbilical arterial and venous catheters were inserted under direct radiographic control. The tip of the arterial catheter was placed in the abdominal aorta below the level of the renal arteries; the venous catheter was placed in the inferior vena cava at the level of the diaphragm. The infant breathed $>95 \% \mathrm{O}_{2}$ in a Perspex head hood. After 20 minutes an arterial blood sample was taken. $p \mathrm{H}, \mathrm{Po}_{2}$, and $\mathrm{PcO}_{2}$ were measured by methods previously described (Owen-Thomas, Ulan, and Swyer, 1968).

Any infant with a $\mathrm{P}_{\mathrm{a}} \mathrm{O}_{2}$ below $100 \mathrm{~mm}$. $\mathrm{Hg}$ in $>95 \%$ oxygen on two consecutive arterial samples was considered suitable for entry into the study.

Forty-four infants entered the study in the 9-month period. These infants were placed in one of two groups. Assignment to a group was by drawing a sealed envelope. One group was designated 'standard therapy' and the other 'mask ventilation'.

'Standard therapy' infants were nursed in servocontrolled incubator units. Therapy was controlled by four- to six-hourly arterial blood gas estimations. The 
inspired oxygen concentration was adjusted to maintain arterial $\mathrm{Po}_{2}$ between $50-80 \mathrm{~mm}$. $\mathrm{Hg}$. Metabolic acidosis was corrected by intermittent injections of $7.5 \%$ sodium bicarbonate into the venous catheter. Fluid and electrolyte requirements were supplied by infusion of $10 \%$ dextrose solution into the venous catheter and $3.3 \%$ dextrose $10 \cdot 3 \%$ saline into the arterial catheter. Hypoglycaemia and hypocalcaemia were treated as necessary. Oral feeds were started within six hours of admission.

'Mask ventilation' infants were also treated with this supportive regimen, but oral feeds were omitted. Assisted ventilation using a tight fitting face mask ${ }^{\star}$ was started. A No. $8 \mathrm{~F}$ oro-gastric tube was passed to prevent gastric distension and glycerine was applied to the face. The face mask was applied firmly to the face, the gastric tube passing through a hole in the mask. The mask was secured by a specially designed harness (Fig. 1a and b). This kept the mask firmly applied to the face with the supporting bands held away from the face. In order to apply therapy effectively, the mask formed an air-tight seal with the face. Some pressure was required to achieve this, and hence the mask was lifted every 30 minutes and completely removed every 60 minutes. At this time the face was massaged, and

^Size 2-4-Bennett Respirations Products Inc., Santa Monica California.

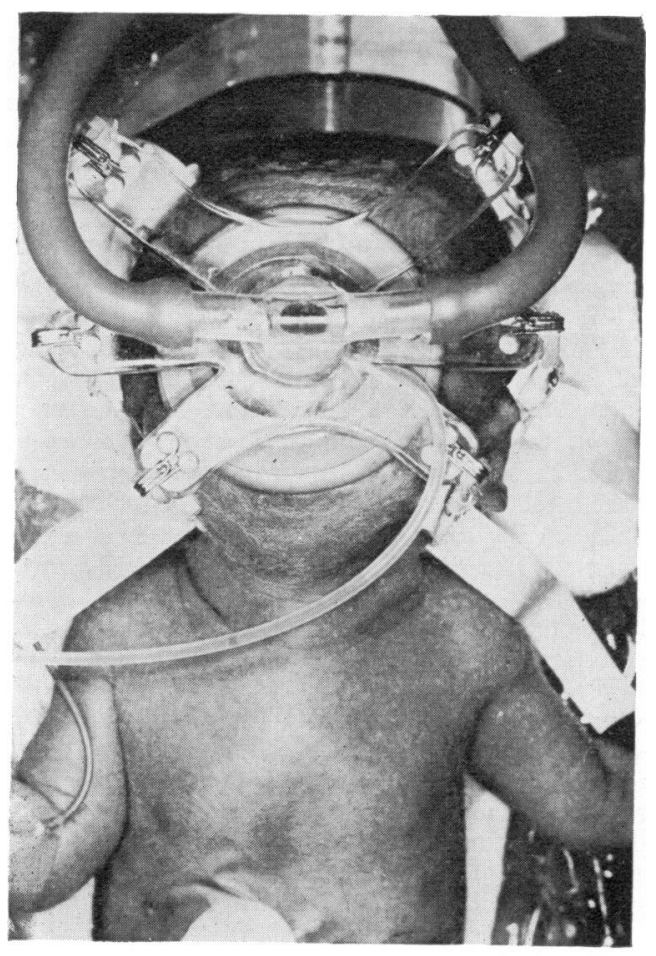

(a)
TABLE I

Comparability of Infants in Standard and Mask Groups

\begin{tabular}{|c|c|c|c|}
\hline & Standard & Mask & \\
\hline & $\begin{array}{c}15 \text { Male } \\
7 \text { Female } \\
\text { Mean } \pm \text { SEM }\end{array}$ & $\begin{array}{c}17 \text { Male } \\
5 \text { Female } \\
\text { Mean } \pm \text { SEM }\end{array}$ & $\mathrm{p}$ \\
\hline Birthweight (g.) & $1782 \pm 118$ & $2002 \pm 126$ & $<0.4$ \\
\hline $\begin{array}{l}\text { Gestation (wk.) } \\
\text { Age of entry into }\end{array}$ & $32.9=0.6$ & $33 \cdot 5 \pm 0.7$ & $<0 \cdot 3$ \\
\hline study (hr.) & $19 \cdot 2 \pm 2 \cdot 7$ & $24 \cdot 7 \pm 3 \cdot 5$ & $<0 \cdot 2$ \\
\hline $\begin{array}{l}\text { Age of admission (hr.) } \\
\text { Admission data }\end{array}$ & $7 \cdot 22 \pm 1 \cdot 2$ & $11 \cdot 9 \pm 2 \cdot 9$ & $<0.01$ \\
\hline $\begin{array}{r}\text { Temp. }\left({ }^{\circ} \mathrm{C} .\right) \\
{\left[\mathrm{H}^{+}\right](\mathrm{n} \mu \mathrm{Eq})}\end{array}$ & $\begin{array}{c}35 \cdot 5 \pm 0 \cdot 27 \\
68 \cdot 0 \pm 2 \cdot 5 \\
(p H 7 \cdot 17)\end{array}$ & $\begin{array}{c}36 \cdot 2 \pm 0 \cdot 19 \\
62 \cdot 5 \pm 2 \cdot 5 \\
(p H 7 \cdot 20)\end{array}$ & $\begin{array}{l}<0.05 \\
<0.1\end{array}$ \\
\hline $\begin{array}{l}\mathrm{P}_{\mathrm{a}} \mathrm{O}_{2}(\mathrm{~mm} . \mathrm{Hg}) \\
\mathrm{P}_{\mathrm{a}} \mathrm{CO}_{2}(\mathrm{~mm} . \mathrm{Hg})\end{array}$ & $\begin{aligned} 126 & \pm 16 \\
42 & \pm 6\end{aligned}$ & $\begin{aligned} 109 & \pm 12 \\
47 & \pm 4\end{aligned}$ & $\begin{array}{l}<0.3 \\
<0.1\end{array}$ \\
\hline
\end{tabular}

suctioning of the oropharynx could be performed if necessary. Either a pressure-cycled ${ }^{\star}$ or a volumecycled $\dagger$ ventilator was used. A maximum inflation pressure of $20 \mathrm{~cm} . \mathrm{H}_{2} \mathrm{O}$ was used. Optimal patient triggering was important in maintaining adequate ventilation and in reducing the incidence of complications.

If the arterial $\mathrm{Po}_{2}$ fell below $45 \mathrm{~mm} . \mathrm{Hg}$ in $100 \% \mathrm{O}_{2}$ on two consecutive arterial samples, infants in either group were then intubated and maintained on mechanical ventilation.

\section{Results}

Comparability of groups. Twenty-two infants were in each group. As shown in Table I, the two groups were comparable for sex, birth-

^Bird Mark VIII-Bird Corporation, Palm Springs, California. †Bourns Pediatric Respirator Model LS-104-Bourns Inc., Riverside, California.

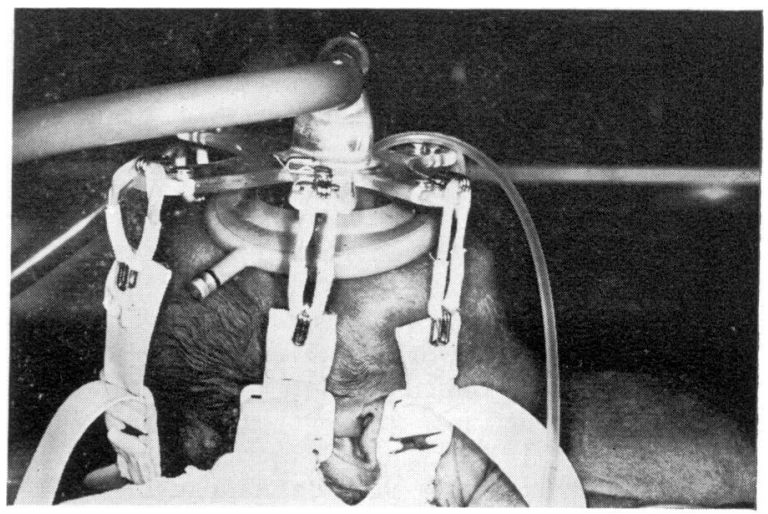

(b)

FIG. 1 (a) and (b)-Face mask in position with supporting harness. 
weight, gestation, and admission blood gas and $p \mathrm{H}$ values. Though the 'standard' group was admitted to the Unit at a significantly earlier age than the 'mask' group, the age of entry into the study was comparable in the two groups. Admission temperature was significantly lower in the 'standard' group than in the 'mask' group.

Incidence of intubation. Of 22 infants in the 'standard' group, 20 infants reached the criterion for intubation, i.e. $\mathrm{P}_{\mathrm{a}} \mathrm{O}_{2}$ less than $45 \mathrm{~mm}$. $\mathrm{Hg}$ in $\sim 95 \% \mathrm{O}_{2}$ on two consecutive arterial samples. Of 22 infants in the 'mask' group, 13 infants reached the criterion for intubation. This difference in incidence of intubation between the two groups is statistically significant $(p<0.05)$ (Table II).

The age at which intubation became necessary was effectively delayed by mask ventilation; mean age of intubation for mask group was $45 \cdot 4 \pm 10 \cdot 9$ hours and for standard group was $27 \cdot 2 \pm 3 \cdot 3$ $(\mathrm{p}<0.05)$ (Fig. 2).

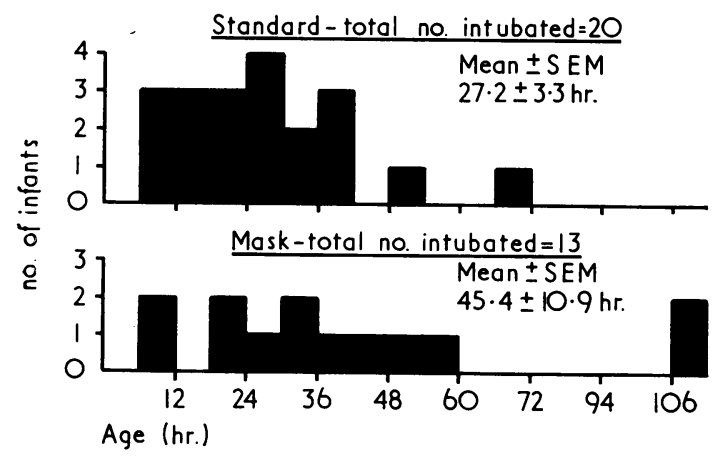

FIG. 2.-Age of intubation of infants in standard and 'mask' groups.

Survival. Despite 'delayed' intubation in the mask ventilation group, ultimate survival did not differ significantly in the two groups. 12 of 22 infants in the mask group survived and 8 of 22 infants in the standard therapy group survived $(\mathrm{p}<0.3)$. The over-all survival rate in this series was $45 \%$.

Of the 12 survivors in the mask group, 9 were mask-ventilated only, the remaining 3 survived intubation after mask ventilation had failed (Table II).

Of the 8 survivors in the standard group, 2 did not require intubation, the remaining 6 survived after a period of intubation and IPPV.

The age at death did not differ significantly in the two groups; mean age at death in standard group
TABLE II

Outcome of Infants in Standard and Mask Groups

\begin{tabular}{l|l|l}
\hline Standard & $22\left\langle\begin{array}{l}\text { Not intubated-2-2survived } \\
\text { Intubated }-20-6 \text { survived }\end{array}\right.$ & $\begin{array}{c}\text { Total } \\
\text { Survivors }\end{array}$ \\
Mask & $22\left\langle\begin{array}{l}\text { Not intubated-9-9 survived } \\
\text { Intubated }\end{array}\right\rangle$ & 12 \\
\hline
\end{tabular}

of $97 \pm 18 \mathrm{hr}$., and in the mask group $103 \pm 33 \mathrm{hr}$. $(\mathrm{p}<0 \cdot 4)$.

Effects of assisting ventilation on arterial blood gas tensions and $p H$. The improvements in biochemical status on starting mask ventilation are seen in Fig. 3. In 7 infants, $P_{\mathrm{a}} \mathrm{O}_{2}$ rose $>75 \mathrm{~mm}$. $\mathrm{Hg}$ while maintaining the infant in $100 \%$ $\mathrm{O}_{2}$. Similar improvements were noted within 4 hours of intubation in both 'standard therapy' group and in the 'mask ventilated' infants who required subsequent intubation.

Length of time in oxygen. Both groups of infants were in $95 \% \mathrm{O}_{2}$ at the time of entry into the study. Concentration of inspired oxygen was reduced as rapidly as possible-maintaining the arterial $\mathrm{PO}_{2}$ between 50 and $80 \mathrm{~mm}$. $\mathrm{Hg}$.

In the 'standard' group the mean duration of increased oxygen in inspired air in surviving infants was $18 \cdot 7 \pm 2 \cdot 7$ days (this excludes one infant who remains in $\mathrm{O}_{2}$ at the age of 5 months). In the 'mask' group, the mean duration of increased oxygen in inspired air in surviving infants was $8 \pm 2 \cdot 1$ days $(\mathrm{p}<0.05)$.

\section{Radiological changes.}

Face mask only. All infants ventilated by face mask only showed characteristic radiographic changes associated with RDS. In all but one infant there was a gradual resolution of $x$-ray changes over 10 days. One infant showed progressive opacification and developed interstitial emphysema at 8 days. At 15 days there was patchy hyperaeration, but by 3 weeks at the time of discharge the radiological appearance was normal. None of these infants has been readmitted since discharge.

Standard therapy only. The 2 infants on 'standard therapy' who did not require intubation both showed a similar pattern of resolution over 5 to 10 days. One of these infants had a small pneumothorax. 
Naso-tracheal intubation and death within 5 days (mask and standard therapy groups). 19 infants were in this group, and all showed progressive loss of aeration and diminution of lung size. Many also

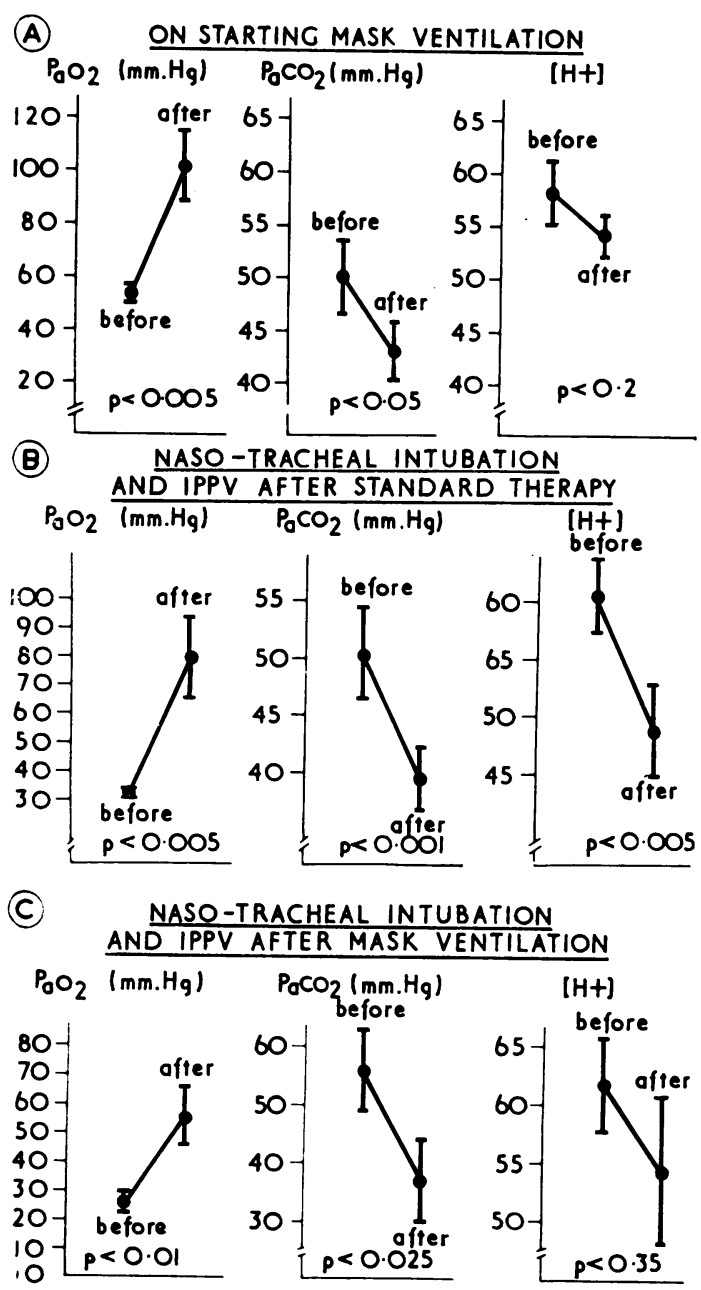

FIg. 3.-Mean change in $\mathrm{Pa}_{a} \mathrm{O}_{2}, \mathrm{P}_{a} \mathrm{CO}_{2}$, and $[\mathrm{H}+]$ on (A) Mask ventilation; $(B)$ naso-tracheal intubation in 'standard' group; and (C) nasotracheal intubation in 'mask' group.

had radiographic evidence of interstitial emphysema, and 4 developed a pneumothorax just before death.

Naso-tracheal intubation and survival after 5 days. The infants with most marked radiographic changes were in this group. There were 12 infants in this group of whom 9 survived. Of these 9 survivors, 5 have an abnormal radiological appearance at age of 4 to 9 months. One infant remains in the Unit, and at the age of 5 months has cor pulmonale and chronic respiratory insufficiency. His $x$-ray changes are those associated with broncho-pulmonary dysplasia. The other 4 infants all showed progression of the radiographic changes of the acute stage to complete opacification of the lung fields and subsequent slow resolution with areas of hyperinflation and streaky densities. Atelectasis of one or more lobes (especially right upper lobe) occurred in the recovery phase in 3 infants. Subsequently 3 of the 4 infants with abnormal $x$-ray appearance at follow-up have required hospital admission for bronchospasm, bronchopneumonia, or recurrent atelectasis.

Complications of mask ventilation. Many infants developed oedema of the face. This resolved rapidly on discontinuing therapy. Some moulding of the skull and facial bones occurred especially in infants under $1500 \mathrm{~g}$. There was one severe complication of mask ventilation; despite the use of an orogastric catheter to prevent gastric distension, gastric perforation occurred in one infant at the age of 110 hours, 83 hours after starting mask ventilation. At laparotomy a gastrostomy tube was inserted into a large perforation in the greater curvature of the stomach. The infant survived and was successfully extubated at age 204 hours. Though spontaneous gastric perforation is described in newborn infants (Saracli et al., 1967), this must be regarded as a complication of therapy. One infant developed a bilateral pneumothorax during mask ventilation. On an earlier pilot study, 3 of 10 infants on mask ventilation developed a pneumothorax. We regard these as possible complications of treatment. However, 4 infants ventilated with a naso-tracheal tube and one infant in the standard group who was not ventilated had pneumothoraces. Hence pneumothorax remains a constant hazard to the infants with severe RDSwhether ventilated or not. 5 or the 6 infants with this complication died despite prompt drainage.

Infection. There was a high incidence of positive bacterial cultures from Auger suction specimens, endotracheal tube suctionings, or at necropsy. Of the 44 infants in the study, 25 had positive bacterial cultures, 22 of these were for Pseudomonas aeruginosa. Endotracheal intubation appeared the most important factor in promoting infection with this organism. 37 infants were intubated during the study - of these 24 had positive 
bacterial cultures 21 having pseudomonas; of 13 infants not intubated, only one had a positive culture for pseudomonas: this infant was mask ventilated for 72 hours and pseudomonas was obtained from Auger suction on the eighth day of life. 12 of the positive bacterial cultures were obtained during life. The remainder were obtained from ventricular blood at necropsy.

Infection with Gram-negative organisms did not appear to be a factor influencing survival, as 8 of the 20 survivors had evidence of pseudomonas infection, as did 14 of the 24 infants who died.*

Prophylactic antibiotics were not used. However, ampicillin (100 mg./kg. per $24 \mathrm{hr}$.) and kanamycin $(15 \mathrm{mg}$. $/ \mathrm{kg}$. per $24 \mathrm{hr}$.) were given if there was overt clinical evidence of infection. Endotracheal suctionings were cultured daily, and if secretions became muco-purulent or yielded a positive bacterial culture, systemic antibiotics were started. In addition, $0.25 \mathrm{ml}$. of a mixture of penicillin (500 units $/ \mathrm{ml}$.) and colistin (500 units $/ \mathrm{ml}$.) was instilled down the endotracheal tube every 4 hours.

Necropsy findings. Of 24 infants who died, 20 had necropsies performed (Table III). These all showed histological evidence of hyaline membrane disease with atelectasis. In addition, 4 infants had a pneumothorax and one had widespread lung abscesses. This infant had generalized sepsis, as did a second infant with purulent pericarditis. Both had been successfully extubated at 82 hours and 230 hours, and then during the subsequent 48 hours had sudden apnoea and rapid deterioration to death.

One infant developed signs of cardiac tamponade soon after initiating assisted ventilation, and died despite attempted paracentesis of the pericardial sac. At necropsy a large blood-stained pericardial effusion was present. The cause was uncertain. The umbilical venous catheter was in the right atrial appendage, but there was no myocardial perforation.

Eight of the 20 infants had intracranial haemorrhage. This high incidence has been reported in other series (Heese et al., 1963; Silverman et al., 1967; Murdock et al., 1970).

\section{Discussion}

Over-all mortality in RDS remains high. Of 183 infants admitted to the Unit in 1967-1968, 66 died (36\% mortality).

The current views on the pathophysiology of

*A bacteriological study later showed Pseudomonas organisms in 500 ml. M.I.E. (Medical Industrial Equipment Ltd., London) inflation bags. The incidence of infection has fallen since these bags have been sterilized by immersion in $70 \%$ alcohol for 30 minutes.
TABLE III

Necropsy Findings in Infants in Standard and Mask Groups

\begin{tabular}{|c|c|c|}
\hline Organ & Standard & Mask \\
\hline $\begin{array}{l}\text { Trachea and larynx } \\
\text { Ulceration }\end{array}$ & 4 & 2 \\
\hline $\begin{array}{l}\text { Lungs } \\
\text { Atelectasis and hyaline membrane disease } \\
\text { Pneumothorax } \\
\text { Lung abscesses }\end{array}$ & $\begin{array}{r}12 \\
2 \\
1\end{array}$ & $\begin{array}{l}8 \\
2\end{array}$ \\
\hline $\begin{array}{l}\text { Liver } \\
\quad \text { Infarction }\end{array}$ & 1 & \\
\hline $\begin{array}{l}\text { Heart } \\
\text { Purulent pericarditis } \\
\text { Pericardial effusion }\end{array}$ & $\begin{array}{l}1 \\
1\end{array}$ & \\
\hline 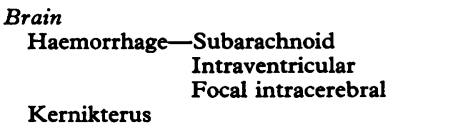 & $\begin{array}{l}4 \\
1 \\
1\end{array}$ & $\begin{array}{l}2 \\
1\end{array}$ \\
\hline
\end{tabular}

Total deaths $=24$. Necropsy $=20$ (12 Standard; 8 Mask).

RDS include the concept of progressive atelectasis, secondary to diminished surfactant (Avery and Mead, 1959; Adams et al., 1965), and alveolar cell damage, related to changes in pulmonary blood flow (Chu et al., 1967). Atelectasis and diminishing functional residual capacity lower pulmonary compliance and increase respiratory work (Cooke et al., 1957). Increasing $\dot{\mathrm{V}} / \dot{\mathrm{Q}}$ imbalance (Nelson et al., 1963) occurs with intrapulmonary shunting and arterial desaturation. It is possible that early intervention with assisted ventilation before the appearance of hypoxia, hypercarbia, and respiratory failure may prevent progressive atelectasis and prevent the familiar vicious circle (Swyer and Levison, 1965).

In this study we have shown that by instituting assisted ventilation with a face mask at an early stage, we have been able not only to alter arterial gas tensions favourably, but also to reduce the number of infants reaching the criterion for intubation, i.e. $\mathrm{P}_{\mathrm{a}} \mathrm{O}_{2}<45 \mathrm{~mm}$. $\mathrm{Hg}$ in $100 \%$ oxygen. The poor prognosis associated with $\mathrm{P}_{\mathrm{a}} \mathrm{O}_{2}<100 \mathrm{~mm}$. $\mathrm{Hg}$ in $100 \%$ oxygen in infants with RDS has been shown previously (Boston, Geller, and Smith, 1966). The outcome of the 'standard' group (20 of 22 infants requiring intubation) supports these earlier findings.

By improving the arterial blood gas tensions with mask ventilation, it was found that the concentration of inspired oxygen could be reduced more rapidly than in infants on standard therapy. In view of current concepts of pulmonary oxygen toxicity (Pratt, 1958; Thibeault, Hagstron, and Auld, 1966), 
this may be important in preventing the superimposed clinical and radiological changes associated with high concentrations of oxygen in inspired air.

Early mask ventilation delays the time at which intubation becomes necessary. As a previous study in this Unit has shown (Murdock et al., 1970), prognosis is more favourable, especially in infants under $2000 \mathrm{~g}$., if intubation becomes necessary only after the age of 36 hours.

The radiological changes are difficult to evaluate, as infants in both groups were intubated when mask ventilation or standard therapy failed. Hence all severely affected infants were intubated and the gross radiological changes were seen in this group. These were infants subjected to prolonged periods of high concentrations of oxygen, and all had positive tracheal cultures. An evaluation of the part played by an endotracheal tube in the evolution of the radiographic changes and persisting pulmonary changes associated with bronchopulmonary dysplasia (Northway, Rosan, and Porter, 1967) can be made only by continuing mask ventilation regardless of blood gas status. A group of this type is incorporated into our current study.

Though the survival rate was higher in the 'mask' group (12/22) than in the 'standard' group (8/22), the difference did not reach statistical significance. Nevertheless, the study showed that mask ventilation in some infants replaced ventilation by endotracheal tube. If this is so, the complications of endotracheal intubation are avoided, and with improvements of technique of mask ventilation, it may be possible to improve survival rates.

Correct technique and the instruction of both nursing and resident staff were important. In order to be effective, the face mask must be correctly applied. Prevention of gastric distension and constant adjustment of the ventilator to provide optimal patient triggering are necessary. Ventilators with sensitive triggering mechanisms and rapid response times are essential. The volume-cycled ventilator used during this study could be triggered by a negative pressure of $0.4 \mathrm{~cm} . \mathrm{H}_{2} \mathrm{O}$ in the expiratory line. The pump was activated within 90 millisec. of initiation of respiration. It could be successfully cycled at rates exceeding $100 / \mathrm{min}$. if necessary. Attempts to control ventilation resulted in gastric distension. If the infant struggled or fought the respirator, the nurses were instructed to loosen the mask until the infant settled again. In view of technical difficulties associated with this technique, we have adopted the nasal mask technique as originally described by Buck and McCormack (1965). This technique is now being evaluated. Bourns Inc. Life Systems of Riverside, California,
kindly made available ventilators for this study.

We would like to thank Dr. B. J. Reilly for radiological $\vec{\equiv}$ assessment, and Miss B. Barnes (head nurse) and the $\mathscr{S}$ nursing staff of the Neonatal Unit for their co-operation. We are also grateful to Miss E. Denoga for biochemical $\bar{\sigma}$ estimations, Mr. C. Lutz for technical help, Mrs. B. Woode for help in compiling the data, and to Miss $\mathbf{P}$. Taggett for secretarial assistance.

REFBRENCES

Adams, F. H., Fujiwara, T., Emmanouilides, G., and Scudder, A. (1965). Surface properties and lipids from lungs of infants with hyaline membrane disease. Fournal of Pediatrics, 66, 357.

Adamson, T. M., Collins, L. M., Dehan, M., Hawker, J. M., Reynolds, E. O. R., and Strang, L. B. (1968). Mechanical ventilation in newborn infants with respiratory failure. Lancet, 2, 227.

Avery, M. E., and Mead, J. (1959). Surface properties in relation to atelectasis and hyaline membrane disease. American fournal of Diseases of Children, $97,517$.

Benson, F., Celander, O., Haglund, G., Nilsson, L., Paulsen, L., and Renck, L. (1958). Positive-pressure respirator treatment of severe pulmonary insufficiency in the newborn infant. $A$ clinical report. Acta Anaesthesiologica Scandinavica, 2, 37.

Boston, W. R., Geller, F., and Smith, C. A. (1966). Arterial blood gas tensions and acid-base balance in the management of the respiratory distress syndrome. Fournal of Pediatrics, 68, 74.

Buck, J. B., and McCormack, W. C. (1965). A nasal mask for premature infants. Fournal of Pediatrics, 66, 123.

Chu, J., Clements, J. A., Cotton, E. K., Klaus, M. H., Sweet, A. Y., and Tooley, W. H. (1967). Neonatal pulmonary ischemia. I. Clinical and physiological studies. Pediatrics, 40, 709.

Cooke, C. D., Sutherland, J. M., Segal, S., Cherry, R. B., Mead, J., McIlroy, M. B., and Smith, C. A. (1957). Studies of respiratory physiology in the newborn infant. III. Measurements of mechanics of respiration. Fournal of Clinical Investigation, 35, 440.

Cooke, R., Lunding, M., Lomholt, N. F., Yssing, M., ZachauChristiansen, B., and Friis-Hansen, B. (1967). Respiratory failure in the newborn. The techniques and results of intermittent positive pressure ventilation. Acta Paediatrica Scandinavica, 56, 498.

Delivoria-Papadopoulos, M., Levison, H., and Swyer, P. R. (1965). Intermittent positive pressure respiration as a treatment in severe respiratory distress syndrome. Archives of Disease in Childhood, 40, 474.

Donald, I., and Lord, J. (1953). Augmented respiration: studies in atelectasis neonatorum. Lancet, $1,9$.

Heese, H. D., Wittmann, W., and Malan, A. F. (1963). The management of the respiratory distress syndrome of the newborn with positive-pressure respiration. South African Medical fournal, 37, 123.

Malan, A., Shepard, F., Blankenship, W., Gray, J., Young, W., and Stahlman, M. (1967). Assisted ventilation in hyaline membrane disease. Society for Paediatric Research, Atlantic City, Program and Abstracts, p. 5.

Murdock, A. I., Linsao, L., Reid, M.McC., Sutton, M. D., Tilak, K. S., Ulan, O. A., and Swyer, P. R. (1970). Artificial mechanical ventilation in the respiratory distress syndrome: A controlled trial. Archives of Disease in Childhood, in the press.

Nelson, N. M., Prod'hom, L. S., Cherry, R. B., Lipsitz, P. J., and Smith, C. A. (1963). Pulmonary function in the newborn infant: the alveolar-arterial oxygen gradient. Fournal of Applied Physiology, 18, 534.

Northway, W. H., Jr., Rosan, R. C., and Porter, D. Y. (1967). Pulmonary disease following respirator therapy of hyalinemembrane disease. Broncho-pulmonary dysplasia. New England fournal of Medicine, 276, 357.

Owen-Thomas, J. B., Ulan, O. A., and Swyer, P. R. (1968). The effect of varying inspiratory gas flow rate on arterial oxygenation during IPPV in the respiratory distress syndrome. British fournal of Anaesthesia, 40, 493.

Pratt, P. C. (1958). Pulmonary capillary proliferation induced by oxygen inhalation. American fournal of Pathology, 34, 1033. 
Reid, D. H. S., Tunstall, M. E., and Mitchell, R. G. (1967). A controlled trial of artificial respiration in the respiratory-distress syndrome of the newborn. Lancet, 1, 532.

Saracli, T., Mann, M., French, D. M., Booker, C. R., and Scott, R. B. (1967). Rupture of the stomach in the newborn infant. Clinical Pediatrics, 6, 583.

Silverman, W. A., Sinclair, J. C., Gandy, G. M., Finster, M., Bauman, W. A., and Agate, F. J., Jr. (1967). A controlled trial of management of respiratory distress syndrome in a bodyenclosing respirator. I. Evaluation of safety. Pediatrics, 39, 740.

Stahlman, M., Young, W., and Payne, G. (1962). Studies of ventilatory aids in hyaline membrane disease. Programme and Abstracts, Society for Paediatric Research, p. 12. (Abstract in American fournal of Diseases of Children, 104, 526.)

Stern, L., Ramos, A. D., Outerbridge, E. W., and Beaudry, P. H. (1968). Negative pressure artificial respiration: use in treatment of respiratory failure of the newborn. Canadian Medical Association fournal, 102, 595.
Swyer, P. R., and Levison, H. (1965). The current status of respiratory distress syndrome of the newly born. Canadian Medical Association fournal, 93, 335.

Thibeault, D. W., Hagstron, J. W. C., and Auld, P. A. M. (1966). Pulmonary oxygen toxicity in a premature infant. Proceedings of Society for Paediatric Research, Atlantic City, Program and Abstracts, p. 85.

Thomas, D. V., Fletcher, G., Sunshine, P., Schafer, I. A., and Klaus, M. H. (1965). Prolonged respirator use in pulmonary insufficiency of the newborn. Fournal of the American Medical Association, 193, 183.

Correspondence to Dr. P. R. Swyer, The Hospital for Sick Children, 555 University Avenue, Toronto 2, Ontario, Canada. 